\title{
The Impact of Streamwise Steps and Cavities Geometry on Supersonic Turbulent Boundary Layer
}

\author{
Kia Chuan $\mathrm{Ch}^{\prime} \mathrm{ng}^{1}$, Dmitriy Anatolevich Teryaev ${ }^{2}$, Junior Sarjit Singh Sidhu ${ }^{1,{ }^{*}}$, Kok Hwa Yu ${ }^{3}$ \\ School of Aerospace Engineering, Universiti Sains Malaysia, Engineering Campus, 14300 Nibong Tebal, Pulau Pinang, Malaysia \\ 2 Institute No. 2 "Aviation, Rocket Engines and Powerplants", Moscow Aviation Institute (National Research University), Volokolamskoe Shosse 4, \\ 125993, Moscow, Russia \\ 3 School of Mechanical Engineering, Universiti Sains Malaysia, Engineering Campus, 14300 Nibong Tebal, Pulau Pinang, Malaysia
}

\section{ARTICLE INFO}

\section{Article history:}

Received 23 September 2020 Received in revised form 22 November 2020

Accepted 24 November 2020

Available online 29 November 2020
Keywords:

Supersonic flow; turbulent boundary

layers; surface roughness; cross-

hatching; cavity

\section{ABSTRACT}

In some cases, the nozzle of a rocket engine could deform during manufacturing or testing, flare up and distort during operation in such a way that periodically repeating structures of depressions and protrusions form on the wall surface. Complex configurations of roughness topologies have been experimentally observed to form due to this fluid-structure interaction. They have been known to distort the boundary layer and increase local drag and heat transfer. A numerical experiment was carried out using ANSYS FLUENT to assess the effects of geometry (streamwise wavelengths $\lambda$ and length-to-depth (L/D) ratios) of discrete roughness topologies in the form of steps and cavities on flow field distortions and resulting total drag. It was found that under slightly over-expanded conditions at Mach 3.0, cavity L/D ratios of 19.8-23.1 and 12.8 -15.5 yielded the highest drag coefficients. The flow fields over these periodic arrays exhibited closed and a combination of closed cavity-type features, and it can be concluded that the flow phenomena associated with separation caused by forwardfacing steps in closed cavity-type topologies contributed the most to the total drag. $\mathrm{L} / \mathrm{D}$ ratios of $6.3-8.4$ exhibited the lowest drag coefficient. The lower drag coefficient is due to the modification of the turbulent boundary layer by the trapped coherent vortical structure within the cavities. Pressure forces become more dominant as the surface wavelength is decreased. For all cases, there was a pronounced increase in the boundary layer thickness after each successive cavity.

\section{Introduction}

The nozzle of the first stage engine of a launch vehicle due to its fixed geometric expansion ratio, operates in off-design modes during most of the active flight trajectory in the rarefied atmosphere, resulting in losses of thrust of up to $7-9 \%$ due to under-expansion of the jet flow [1]. One way to

\footnotetext{
* Corresponding author.

E-mail address: sarjitsidhu@usm.my (Junior Sarjit Singh Sidhu)
} 
reduce these losses and increase the efficiency of a rocket engine at altitude is to increase the expansion area ratio of the nozzle with a nozzle attachment [2-6].

Here there is a trade-off between improved performance, i.e. an increase in thrust and specific impulse and the additional dimensions and mass added to the engine itself due to the nozzle extension, deployment system, etc. At present, only heavy metallic superalloy and foreign composite nozzle attachments are being used on the upper stage engines of several heavy-lift launch vehicles [7]. To reduce the mass of the nozzle attachment, it can be made uncooled and of composite materials.

During standard operation of a rocket engine with a nozzle attachment, inevitably the turbulent supersonic flow of the combustion products with high stagnation enthalpy over the nozzle attachment's walls occurs. Wherein, suppose the streamlined walls of the nozzle attachment are made of composite materials, then after exceeding the limits of the material's heat resistance, ablation begins, during which non-uniform structures of alternating protrusions and depressions form on the composite walls. Complex configurations of roughness topologies have been experimentally observed to form due to this fluid-structure interaction [8]. These ablation patterns can form not only within the nozzles of liquid rocket engines and solid propellant rocket motors but also on the warheads of rockets, in the combustion chambers of scramjet engines and on the thermal protection system (TPS) of supersonic and hypersonic vehicles.

After the formation of the distributed surface roughness elements on the initially smooth walls of the higher-altitude nozzle attachment, its contribution to the engine's thrust is reduced by an amount among other forms of losses, equal to the wave drag of its relief walls. With subsequent ablation of the material, the height of the protrusions and the depth of the depressions increases, and with them, the loss of thrust due to wave drag continue to rise. From the aforementioned, comes the relevance of studying the supersonic flow fields over distributed roughness structures and their effects on the turbulent boundary layer (TBL).

Laganelli and Zempel [9] investigated the emergence of cross-hatched surface patterns on the surface of ablating cones. Early work surrounding this fluid dynamics phenomenon focused on establishing the fundamental physics behind their formation [10]. It was established that a sufficiently thin supersonic transitional or turbulent boundary layer is a necessary condition for the patterns to appear. In Russia, Semenov and Sergienko [11, 12] performed experimental studies on the wave drag of nozzle attachments with stepped relief walls, as well as analogue plates. The existence of several crises during flow over the relief surfaces was noticed, which resulted in sharp increases in wave losses.

Latin and Bowersox [13] experimentally measured and characterized the effects of a number of rough-walled topologies including equivalent sand-grain roughness and distributed machined roughness on the mean and turbulent flow quantities of a Mach 2.9 supersonic TBL. It was found that smaller roughness elements relative to the boundary layer thickness increased skin friction losses. As the heights of the elements increased, a corresponding increase in turbulent production levels was noted.

Ekoto et al., [14] conducted a PIV study on square and diamond distributed roughness of d-type and k-type elements. The diamond roughness's flow field was found littered with shockwaves and expansion fans which altered both the turbulence production and structure of the boundary layer. Data of the local pressure field showed periodic alternating high-and low-pressure regions which corresponded to the formation of shockwaves and expansion fans at the fore and rear parts of the elements respectively.

Semenov et al., $[15,16]$ studied periodic roughness topologies in the form of plane waves and presented formulas derived analytically to describe the dependence of the total wave drag 
coefficient on similarity parameters. They proved that finite periodic plane reliefs with a fractional value of the wavenumber have one incomplete period, the contribution of which to the total wave drag coefficient could either be negative or positive.

Van Pelt et al., [17] carried out a study on the relationship between wall forces, heat transfer and roughness geometries characteristic of the inner surface of a cooled rocket nozzle. Their findings concluded that step type topologies contributed the most to drag compared to cavity-type roughness elements.

At present, research and data on distributed surface roughness effects on a compressible TBL are at best scarce and scattered relating to specific flow conditions and roughness topologies. With that in mind, the objective of this study is to provide an insight into the fluid dynamics of high-speed mechanically distorted TBL and quantify the resulting drag coefficient. In this paper, the streamwise effect of wavelength $\lambda$ and the length-to-depth ratio (L/D) of discrete roughness topologies in the form of steps and cavities representative of surface irregularities post-ablation on a compressible fully-developed TBL at Mach 3.0 under slightly over-expanded conditions are systematically investigated numerically using RANS simulations.

\section{Methodology}

The methodological approach employed herewith involved a parametric numerical study carried out using the commercial computational fluid dynamics (CFD) software package ANSYS FLUENT 19.2.

\subsection{Physical Geometry}

The more complex profiles of protrusions and depressions characteristic of post-ablated surface roughness were reduced to simple steps and cavities. Axisymmetric flat plates with identical periodic embossed roughness elements on the top and bottom surface with varying wavelengths $\lambda$ and cavity $\mathrm{L} / \mathrm{D}$ ratios were used in the simulations. The transition from the axisymmetric shell of the nozzle attachment to a flat panel is possible due to the small displacement of its contour from the original theoretical profile relative to the distance from the axis given by

$$
\xi / R \ll 1
$$

where $\xi$ is the transverse displacement of the contour, and $\mathrm{R}$ is the radius in the current section of the nozzle attachment.

The plate model has the following dimensions: length $\mathrm{L}=50 \mathrm{~mm}$, total thickness $\mathrm{s}=3 \mathrm{~mm}$, protrusion height $\delta=0.5 \mathrm{~mm}$ and a sharp leading edge (LE) at $7^{\circ}$ half-angle. The plate geometry is depicted in Figure 1, and the parameters of the wavelengths $\lambda$ and cavity L/D ratios for all case studies are presented in Table 1. A smooth-walled, flat plate geometry is also included to establish the unperturbed state of the TBL and flow field.

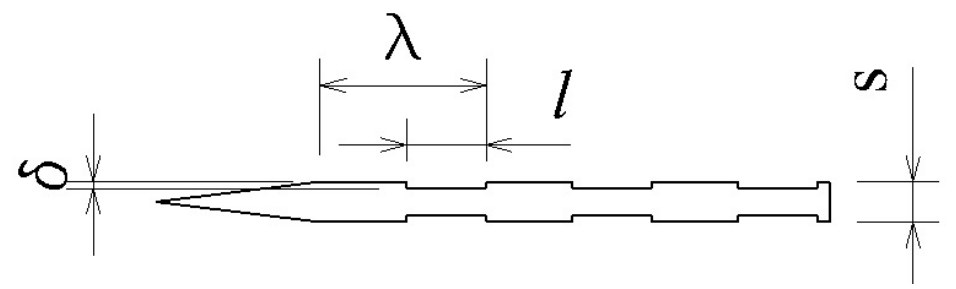

Fig. 1. Flat plate and the definition of important geometric parameters 
Table 1

Geometrical representative and parameters of the roughness topologies

\begin{tabular}{|c|c|c|c|c|}
\hline Plate geometry & $\begin{array}{l}\text { Case } \\
\text { Designation }\end{array}$ & $\begin{array}{l}\text { Wavelength, } \\
\lambda(\mathrm{mm})\end{array}$ & $\begin{array}{l}\text { Cavity length, } \\
l(\mathrm{~mm})\end{array}$ & $L / D$ \\
\hline & Flat plate & - & - & - \\
\hline & $\mathrm{R}-6$ & 37.78 & 12.91 & 25.8 \\
\hline & R-8 & 35.92 & 17.24 & 34.5 \\
\hline & $\mathrm{R}-10$ & 28.79 & 13.82 & 27.6 \\
\hline & R-12 & 24.05 & 11.54 & 23.1 \\
\hline & $R-14$ & 20.67 & 9.92 & 19.8 \\
\hline & $\mathrm{R}-16$ & 18.14 & 8.71 & 17.4 \\
\hline & R-18 & 16.18 & 7.77 & 15.5 \\
\hline & R-20 & 14.62 & 7.02 & 14.0 \\
\hline & $R-22$ & 13.35 & 6.41 & 12.8 \\
\hline & $R-24$ & 12.29 & 5.90 & 11.8 \\
\hline & R-35 & 8.71 & 4.18 & 8.4 \\
\hline & $\mathrm{R}-40$ & 7.77 & 3.73 & 7.5 \\
\hline & R-45 & 7.07 & 3.39 & 6.8 \\
\hline & R-50 & 6.52 & 3.13 & 6.3 \\
\hline
\end{tabular}

\subsection{Governing Equations}

In the study of turbulent supersonic flow over roughness topologies, Favre-averaged system of Navier-Stokes equations was used when simulating turbulent flows with density fluctuations. The dynamics of the flow can be described by the conservation of mass, momentum and energy given below

$$
\begin{aligned}
& \frac{\partial \bar{\rho}}{\partial t}+\frac{\partial}{\partial x_{i}}\left(\bar{\rho} \tilde{u}_{i}\right)=0 \\
& \frac{\partial}{\partial t}\left(\bar{\rho} \tilde{u}_{i}\right)+\frac{\partial}{\partial x_{j}}\left(\bar{\rho} \tilde{u}_{j} \tilde{u}_{i}\right)=-\frac{\partial P}{\partial x_{i}}+\frac{\partial}{\partial x_{j}}\left(\bar{t}_{j i}-\bar{\rho} \tau_{j i}\right)
\end{aligned}
$$

where pressure is given by the equation of state, $P=\bar{\rho} R \widetilde{T}$, and Favre-averaged Reynolds-stress tensor, $\bar{\rho} \tau_{\mathrm{ij}}=-\overline{\rho \mathrm{u}^{\prime \prime}{ }_{1} \mathrm{u}^{\prime \prime}}{ }_{\mathrm{j}} \cdot \tau_{\mathrm{ij}}$ is a symmetric tensor.

$$
\begin{aligned}
& \frac{\partial}{\partial t}\left[\bar{\rho}\left(\tilde{e}+\frac{1}{2} \tilde{u}_{i} \tilde{u}_{i}+k\right)\right]+\frac{\partial}{\partial x_{j}}\left[\bar{\rho} \tilde{u}_{j}\left(\tilde{h}+\frac{1}{2} \tilde{u}_{i} \tilde{u}_{i}+k\right)\right] \\
& =\frac{\partial}{\partial x_{j}}\left[\tilde{u}_{i}\left(\bar{t}_{i j}+\bar{\rho} \tau_{i j}\right)+\left(\frac{\mu}{P r_{L}}+\frac{\mu_{T}}{P r_{T}}\right) \frac{\partial \tilde{h}}{\partial x_{j}}+\left(\mu+\sigma^{*} \frac{\bar{\rho} k}{\omega}\right) \frac{\partial k}{\partial x_{j}}\right]
\end{aligned}
$$

where $\operatorname{Pr}_{\mathrm{L}}$ and $\operatorname{Pr}_{\mathrm{T}}$ are the laminar and turbulent Prandtl number respectively, $\sigma^{*}$ is the closure coefficient, and $\omega$ is the specific dissipation rate as based on the $\mathrm{k}-\omega$ model.

Viscosity is computed from Sutherland's law given by

$$
\mu=\mu_{0}\left(\frac{T}{T_{0}}\right)^{3 / 2}\left(\frac{T_{0}+S}{T+S}\right)
$$




\subsubsection{Transport equations}

In this work, the widely used Menter's shear stress transport (SST) variant of the $\mathrm{k}-\omega$ turbulence model was used based on its ability to resolve wall-bounded flow with adverse pressure gradients [18-20]. The SST model solves transport equations for the turbulent kinetic energy $\mathrm{k}$ and the specific dissipation rate $\omega$

$$
\frac{\partial}{\partial t}(\bar{\rho} k)+\frac{\partial}{\partial x_{j}}\left(\bar{\rho} \tilde{u}_{j} k\right)=\bar{\rho} \tau_{i j} \frac{\partial \tilde{u}_{i}}{\partial x_{j}}-\beta^{*} \bar{\rho} k \omega+\frac{\partial}{\partial x_{j}}\left[\left(\mu+\sigma_{k} \mu_{T}\right) \frac{\partial k}{\partial x_{j}}\right]
$$

where $\beta^{*}$ and $\sigma_{\mathrm{k}}$ are closure coefficients.

$$
\begin{aligned}
& \frac{\partial}{\partial t}(\bar{\rho} \omega)+\frac{\partial}{\partial x_{j}}\left(\bar{\rho} \tilde{u}_{j} \omega\right)=\frac{\gamma \bar{\rho}}{\mu_{T}} \tau_{i j} \frac{\partial \tilde{u}_{i}}{\partial x_{j}}-\beta \bar{\rho} \omega^{2} \\
& +2\left(1-F_{1}\right) \frac{\bar{\rho} \sigma_{\omega 2}}{\omega} \frac{\partial k}{\partial x_{j}} \frac{\partial \omega}{\partial x_{j}}+\frac{\partial}{\partial x_{j}}\left[\left(\mu+\sigma_{\omega} \mu_{T}\right) \frac{\partial \omega}{\partial x_{j}}\right]
\end{aligned}
$$

where $\gamma$ is the blending factor, $F_{1}$ is an auxiliary function, while $\beta, \sigma_{\omega 2}$, and $\sigma_{\omega}$ are the closure coefficients for the specific dissipation rate equation.

The values of the closure coefficients used in the FLUENT simulations are as follows: $\beta^{*}=0.09$, $\sigma_{\mathrm{k} 1}=1.176, \sigma_{\mathrm{k} 2}=1.0, \beta_{1}=0.075, \beta_{2}=0.0828, \sigma_{\omega 1}=2.0, \sigma_{\omega 2}=1.168, \mathrm{a}_{1}=0.31, \kappa=0.41$.

\subsection{Numerical Setup and Boundary Conditions}

To take advantage of the axisymmetric nature of the flat plates and the computational setup as well as reduce computing resources only half the domain was simulated. A domain size of $270 \times 30$ $\mathrm{mm}$ was used. A model of a viscous heat-conducting gas is used as a basic model of the medium.

The implicit Advection Upstream Splitting Method (AUSM) scheme was used for the flux vector computation. The chosen AUSM scheme has shown both efficiency and accuracy in solving complex wave interaction problems that involve flow separation under different flow conditions. The computational domain can be seen in Figure 2 and the summary of the setup and boundary conditions used is presented in Table 2.

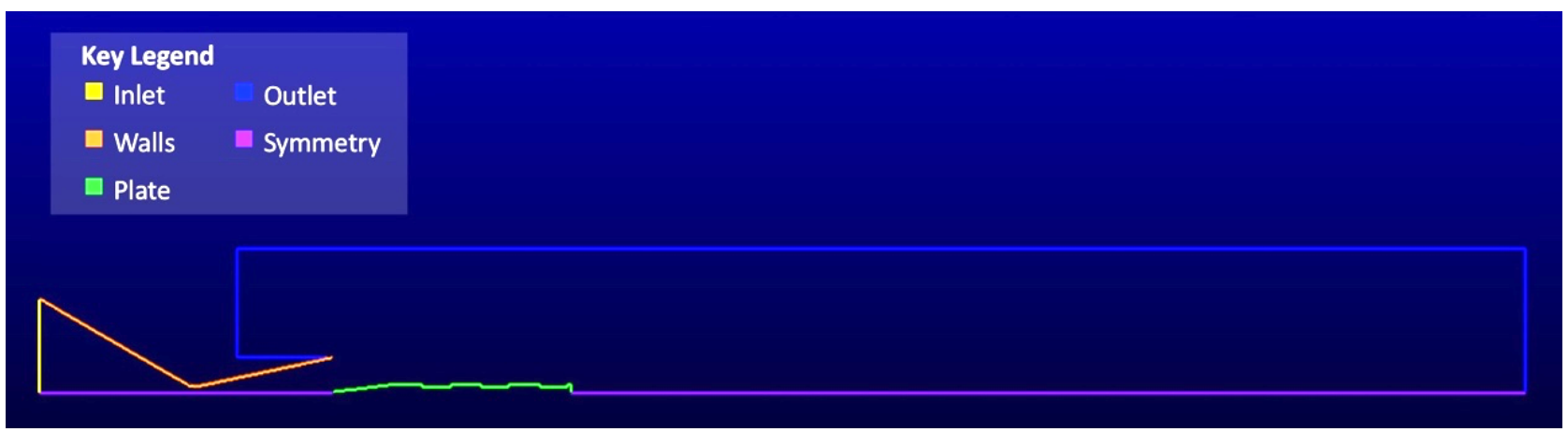

Fig. 2. Computational domain 


\section{Table 2}

\begin{tabular}{|c|c|}
\hline Solver & Steady-state density-based \\
\hline Viscous model & $\mathrm{k}-\omega \mathrm{SST}$ with compressibility effects \\
\hline \multirow[t]{4}{*}{ Fluid properties } & Air (ideal gas) \\
\hline & Specific heat $\mathrm{c}_{\mathrm{p}}=1006.43 \mathrm{~J} / \mathrm{kg} \cdot \mathrm{K}$ \\
\hline & Thermal conductivity $=0.0242 \mathrm{~W} / \mathrm{m} \cdot \mathrm{K}$ \\
\hline & Molecular weight $=28.966 \mathrm{~kg} / \mathrm{kmol}$ \\
\hline \multirow[t]{4}{*}{ Boundary conditions } & Inlet - Pressure inlet $=4 \mathrm{MPa}, 300 \mathrm{~K}$ \\
\hline & Outlet - Pressure outlet $=101325 \mathrm{~Pa}, 300 \mathrm{~K}$ \\
\hline & Walls - Stationary wall with non-slip condition \\
\hline & Plate - Stationary wall with non-slip condition \\
\hline Operating conditions & 0 Pa without gravity effects \\
\hline Reference values & Compute from inlet referring to the interior domain \\
\hline Solution methods & Implicit formulation and AUSM flux type \\
\hline Order scheme & Second-order upwind for all spatial discretisation \\
\hline Initialisation & Standard initialization with an absolute reference frame \\
\hline
\end{tabular}

\subsection{Meshing Approach}

For the complex computational domain, a structured computational grid with quad cells was used and is depicted in Figure 3. When calculating viscous internal flows, the computational grid must be sized to allow all the characteristic features of the flow to be resolved, including the gradients of the parameters in the boundary layer near the walls. The mesh is refined in the near-wall regions to obtain a $y+$ of less than 1 . The overall mesh skewness was controlled such that the maximum skewness is below 0.5 .

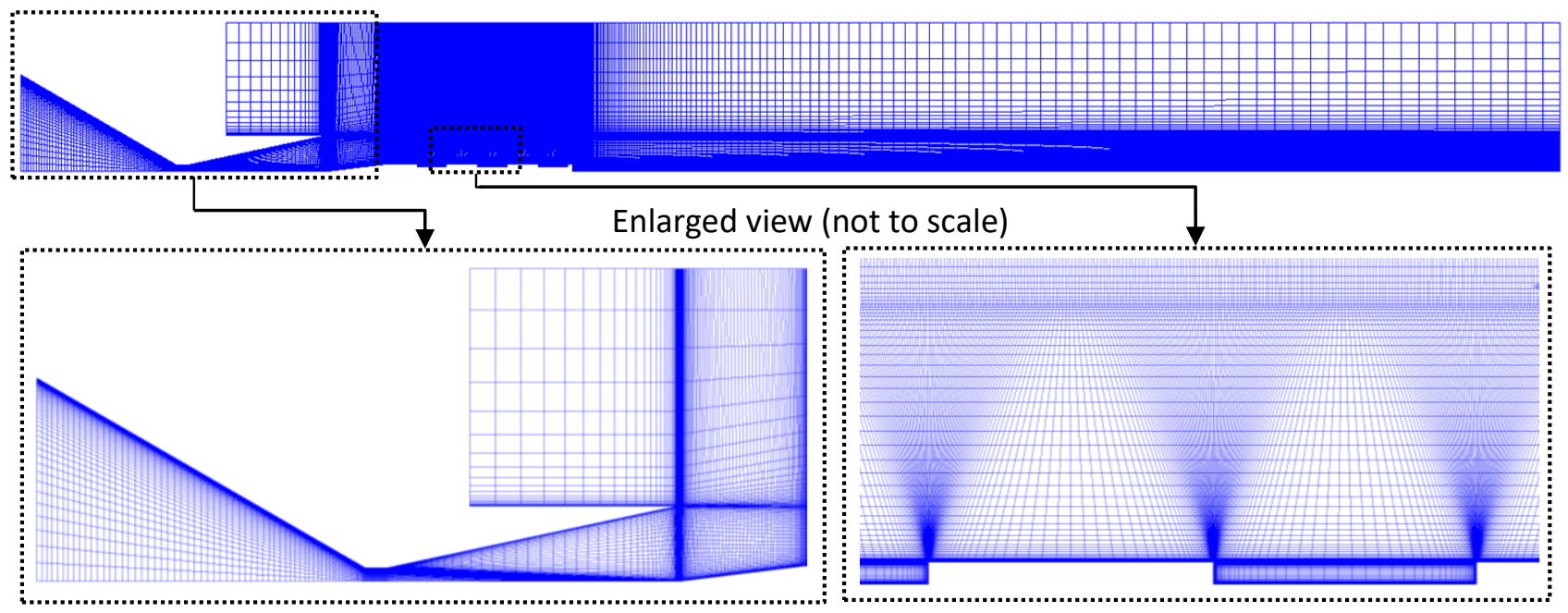

Fig. 3. Computational domain and the grid structure around the roughness topologies

\subsubsection{Grid-independent test and validation}

Case R-24 was used as a case study for the grid-independent test. 5 variations of grid density of $42 \mathrm{~K}, 71 \mathrm{~K}, 101 \mathrm{~K}, 131 \mathrm{~K}$ and $160 \mathrm{~K}$ elements were created. Both mass flow rate and total drag force were monitored and the effects of mesh density on both parameters are presented in Table 3 . The average time taken to complete 1000 iterations was noted as well. 


\section{Table 3}

Grid independence test

\begin{tabular}{|c|c|c|c|c|c|c|}
\hline \multirow[t]{2}{*}{ Model case } & \multirow{2}{*}{$\begin{array}{l}\text { Average time per } 1000 \\
\text { iterations (mins) }\end{array}$} & \multicolumn{3}{|c|}{ Mass flow rate $(\mathrm{kg} / \mathrm{s})$} & \multirow{2}{*}{$\begin{array}{l}\text { Total drag force } \\
\text { (N) }\end{array}$} & \multirow{2}{*}{$\begin{array}{l}\text { Discretization } \\
\text { error }\end{array}$} \\
\hline & & Inlet BC & Outlet BC & Imbalance & & \\
\hline $\mathrm{R}-24(42 \mathrm{~K})$ & 6 & 11.5780 & -11.5760 & 0.0020 & 180.85 & $8.16 \%$ \\
\hline R-24 (71K) & 10 & 11.5655 & -11.5597 & 0.0058 & 178.51 & $6.76 \%$ \\
\hline $\mathrm{R}-24(101 \mathrm{~K})$ & 13 & 11.5633 & -11.5572 & 0.0061 & 169.19 & $1.19 \%$ \\
\hline $\mathrm{R}-24(131 \mathrm{~K})$ & 16 & 11.5618 & -11.5621 & -0.0002 & 167.34 & $0.08 \%$ \\
\hline $\mathrm{R}-24$ (160K) & 21 & 11.5630 & -11.5586 & 0.0044 & 167.20 & Ref. \\
\hline
\end{tabular}

From Table 3 it is clear that the discretization error becomes less significant for an increase in element count from $131 \mathrm{~K}$ to $160 \mathrm{~K}$. Since the additional computational costs don't justify the negligible increase in accuracy, the $131 \mathrm{~K}$ grid element count was selected for all subsequent case studies.

The accuracy of the numerical method in predicting the shock features associated with the cavity flow field is analytically validated using classical oblique shock relations. The $\theta-\beta-M$, deflection angle-wave angle-Mach relationship is applied to the two-dimensional sharp leading edge of the flat plate and the results of the property ratios and wave angle are compared to those obtained numerically. The validation results are presented in Table 4 for the weak shock solution for the idealgas specific heat ratio value of 1.4 . The percentage difference of less than $1 \%$ for the property ratios and $6.6 \%$ for the wave angle shows that the numerical method employed is reliable and the results obtained herewith valid.

\section{Table 4}

Validation of the shock prediction capability of the numerical method

\begin{tabular}{llllll}
\hline Input Parameters: & \multicolumn{5}{l}{} \\
& \multicolumn{4}{l}{$\mathrm{M}_{1}=3.2$} \\
& $\mathrm{M}_{2}$ & Wave angle, $\beta$ & $\mathrm{P}_{2} / \mathrm{P}_{1}$ & $\rho_{2} / \rho_{1}$ & $\mathrm{~T}_{2} / \mathrm{T}_{1}$ \\
\hline Analytical & 2.83 & $23.45^{\circ}$ & 1.72 & 1.47 & 1.17 \\
Numerical & 2.8109 & $\approx 25^{\circ}$ & 1.7375 & 1.4705 & 1.1815 \\
Percentage difference, $\%$ & 0.67 & 6.61 & 1.02 & 0.03 & 0.98 \\
\hline
\end{tabular}

\section{Results}

\subsection{Time Mean Pressure and Pressure Gradient Contours}

A numerical method was employed to provide qualitative insight into the flow field distortions caused by periodic surface roughness elements in the form of steps and cavities. For all case studies, it was found that the compressibility effects caused by the topologies permeated the entire boundary layer and extended into the freestream bounded by the constant-pressure free shear layer. A closeup of the streamwise pressure gradient (PG) contour for case study R-24 is presented in Figure 4 to depict the general flow topologies. The bright white diagonal lines are indicative of strong gradients, whereas black lines are indicative of expansion fans. The incident oblique shock 1 originating from the nozzle lip is due to the slight over-expanded flow condition. Oblique shock 2 at the LE at an angle of $\approx 25^{\circ}$ is consistent with the $\theta-\beta$ shock relation and is followed by expansion fan 3 . The interaction and reflection of shocks and expansion waves with both the constant-pressure free shear layer 4 and the boundary layer are visible on both sides of the flat panel. This is followed by lip shock 5 and trailing edge shock 6 at the base region of the plate. The features described so far is common for all case studies. The differentiating factor is the number and intensity of the shocks and expansion 
fans which were found to correlate strongly to the number of periodic topologies and cavity flow type.

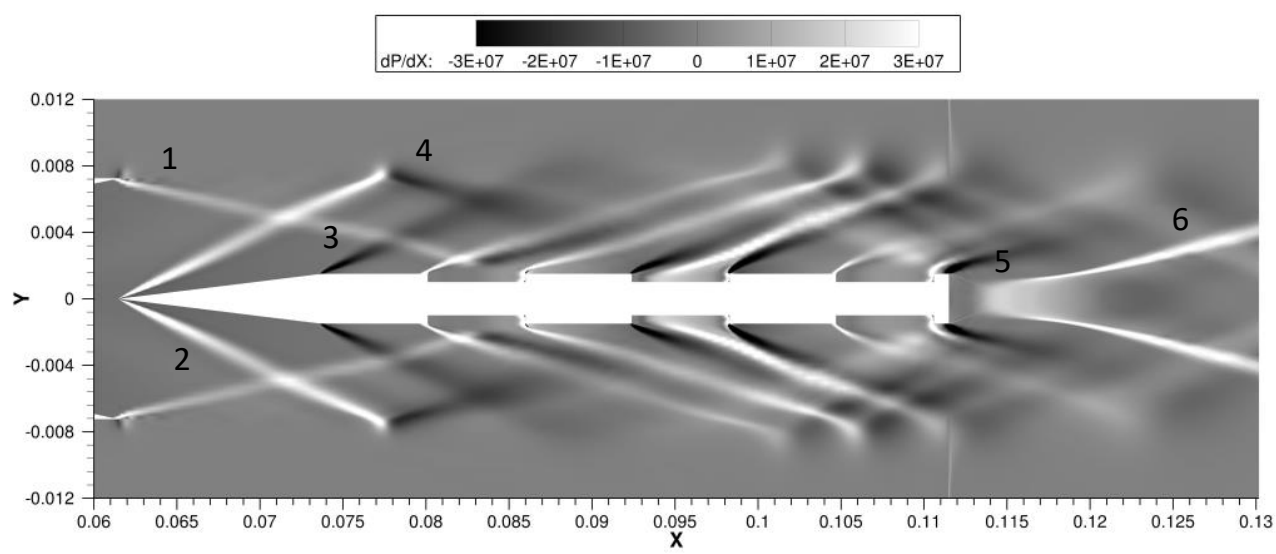

Fig. 4. Streamwise pressure gradient contour for case study R-24. Flow is from left to right

\subsubsection{Cavity flow regimes}

Cropped contours of pressure overlaid with streamlines and $\mathrm{x}$-direction pressure gradient for all case studies are presented in Table 5 together with a summary of their respective cavity flow regime categorization. Results for the flat plate are included to establish a baseline unperturbed boundary layer and flow field. It should be noted that the geometry of case study R-6 does not correspond to any type of cavity and should be viewed as a flat plate geometry with a backwards-facing step (BFS).

\section{Table 5}

Categorization of cavity flow type

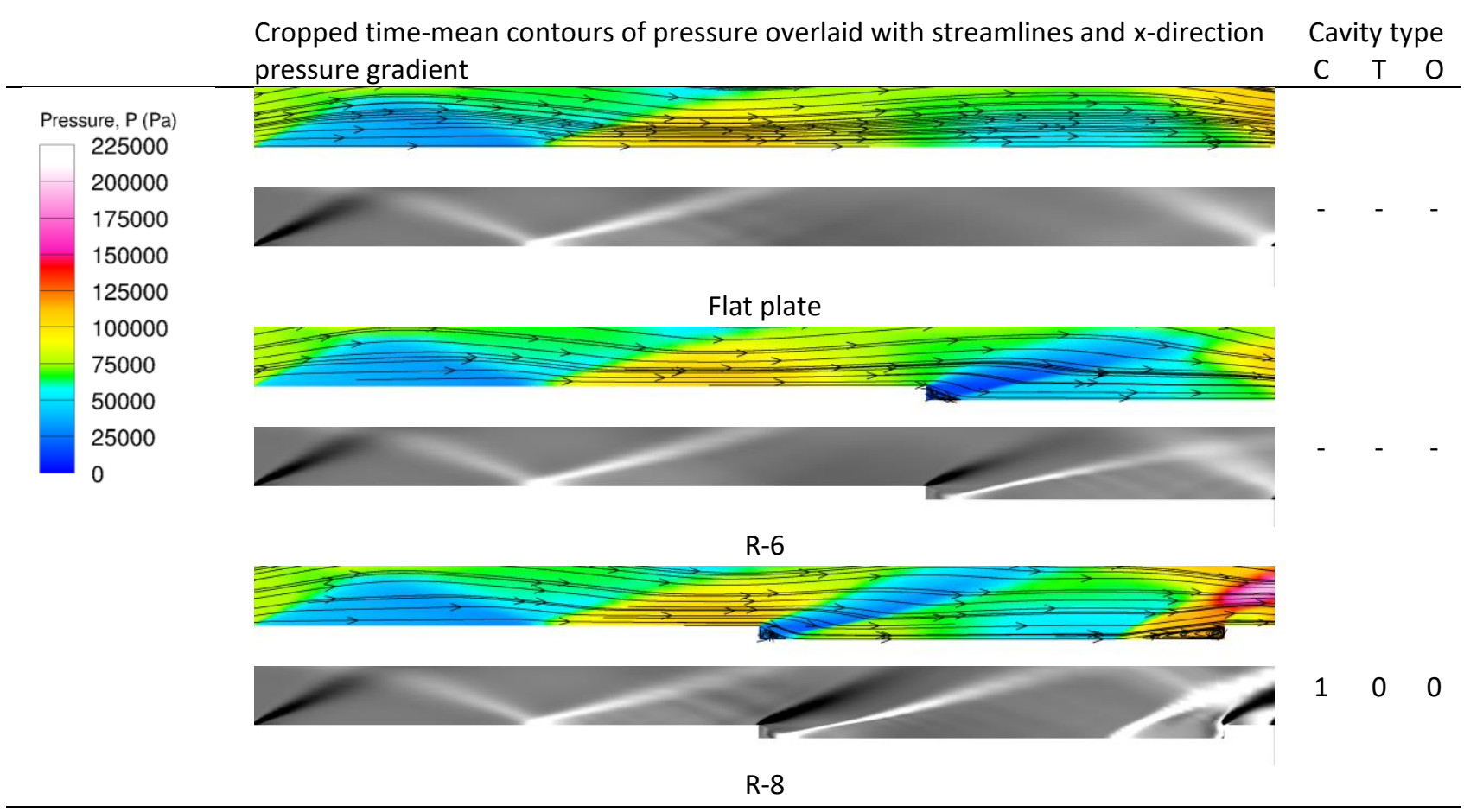



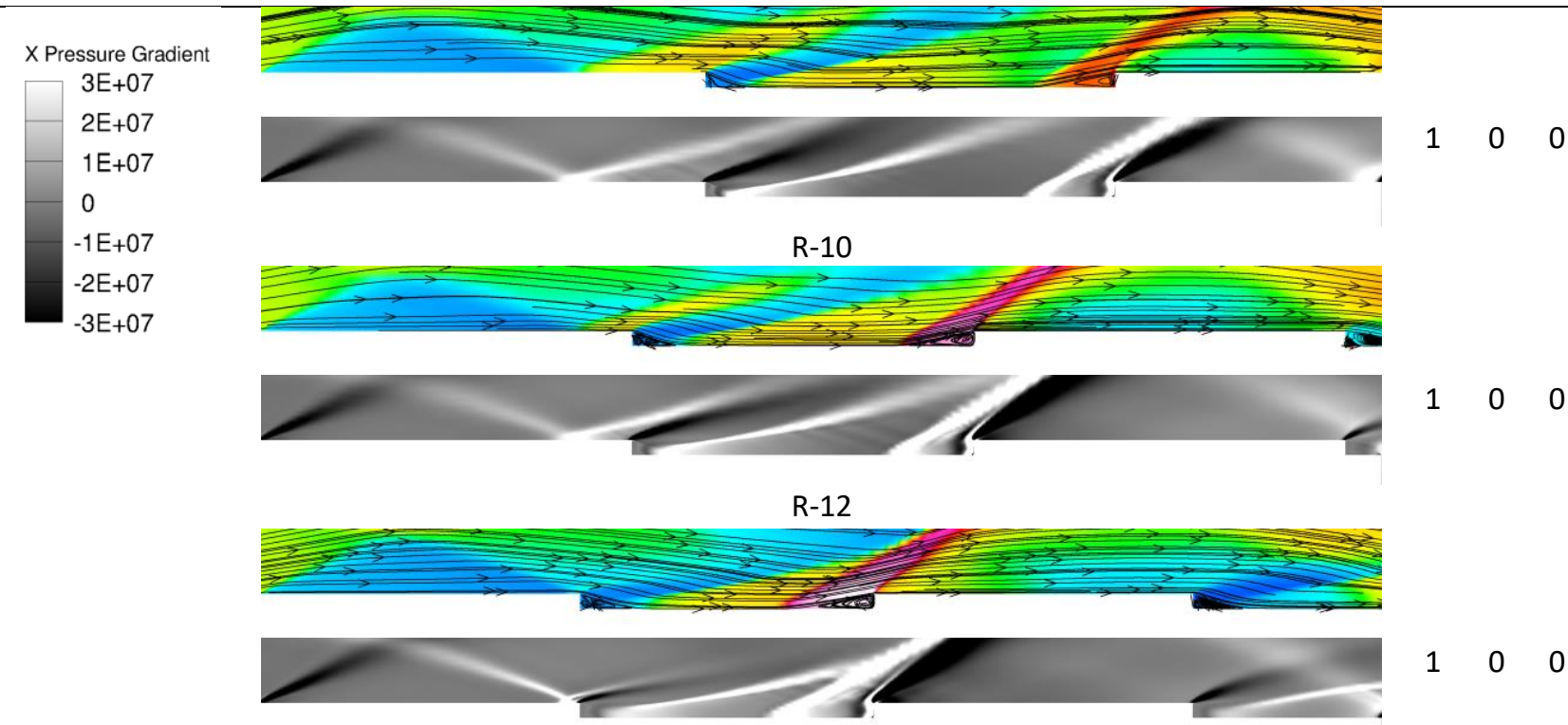

$\mathrm{R}-14$

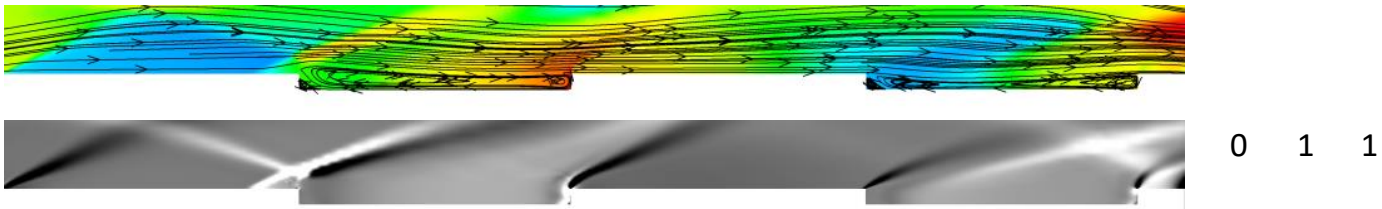

$\mathrm{R}-16$
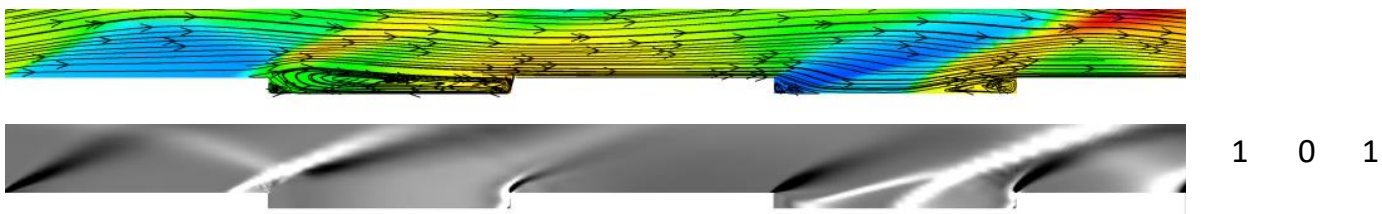

$\mathrm{R}-18$
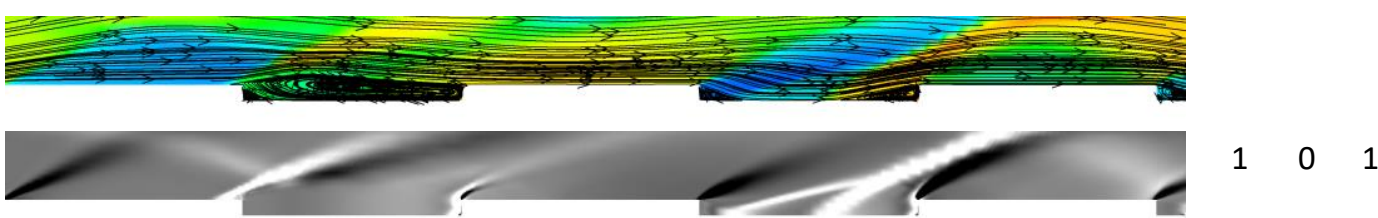

$\mathrm{R}-20$

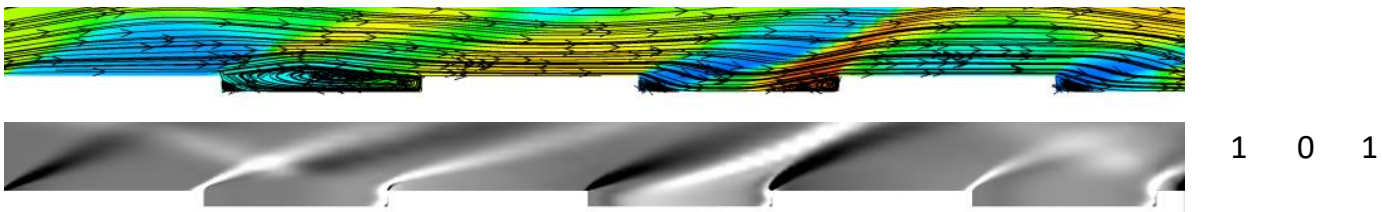

$\mathrm{R}-22$

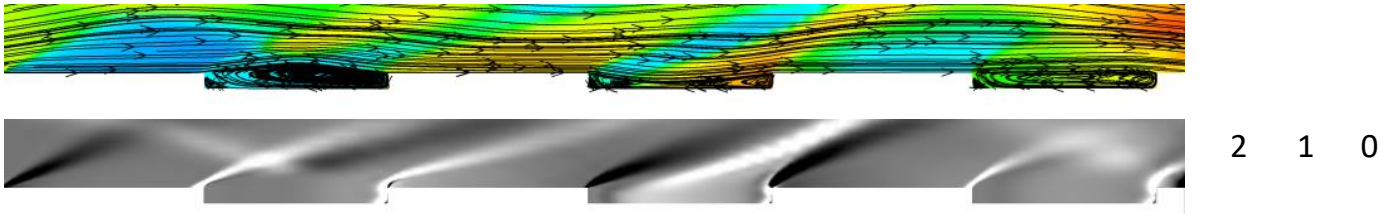

$\mathrm{R}-24$

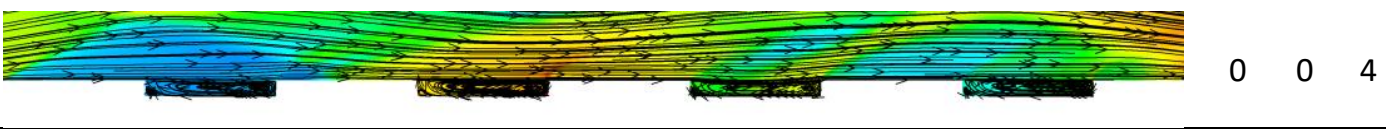




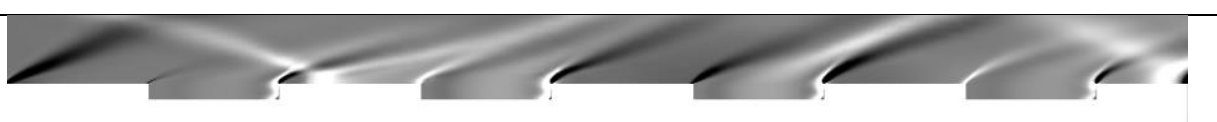

R-35
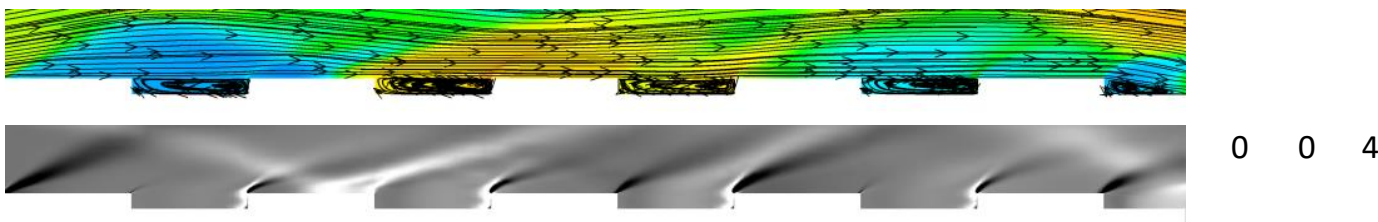

$\mathrm{R}-40$

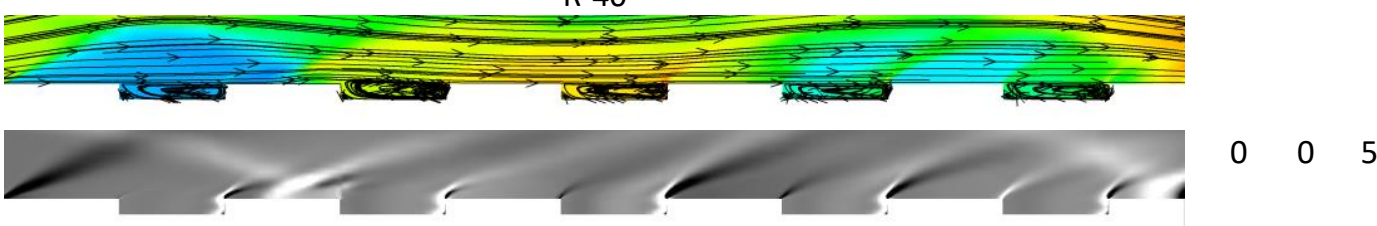

$\mathrm{R}-45$

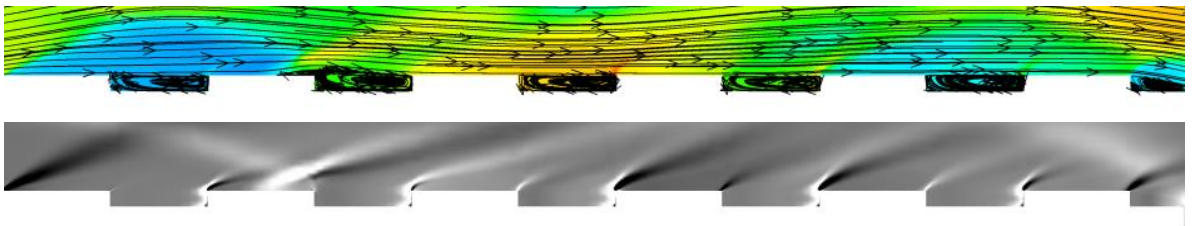

$\mathrm{R}-50$

Case study R- 6 exhibited flow field behaviour typical of a BFS as found in the literature. Case studies R-8 - R-14 with diminishing L/D ratios of 34.5-19.8 displayed closed cavity flow behaviour which is characterized by the impingement of the shear layer on the cavity floor and the resulting two separated recirculation zones. Unlike case R-6 there is an additional separation bubble at the rear part of the cavity. The separated region is accompanied by a separation shock and reattachment shock at the tip of the forward-facing step (FFS) at the end of the cavity. This is evidenced by the highpressure region surrounding the separation and reattachment shocks. Case study R-16 with an L/D ratio of 17.4 evinced a combination of open and transitionary cavity flow behaviour in the first and second cavity respectively. For the first cavity, the streamlines showed evidence of a shear layer spanning the length of the cavity over a single, large recirculation region.

In contrast, for the second, the streamlines partly enter the cavity, bending the surface of the recirculation zone downwards at the centre. R-18 - R-22 with decreasing L/D ratios of $15.5-12.8$ exhibited a combination of open and closed cavity flow type in the first and successive cavities respectively. R-24 showed a combination of open and transitionary cavity flow behaviour. L/D ratios of less than 8.4 revealed pure open cavity-type flow. In general, with a reduction of the wavelength $\lambda$ and cavity L/D ratio of the examined topologies, there is a shift from closed-cavity to open cavitytype flow regimes. For all cases, flow over the steps demonstrated flat plate flow with a noticeable increase in the boundary layer thickness after each successive cavity.

\subsection{Total Drag Coefficient}

The total drag coefficient for all case studies as a function of the cavity L/D ratio is presented in Figure 5 and grouped based on the cavity flow regimes discussed in the previous section. Figure 6 shows the percentage breakdown of the total drag force attributed to pressure and skin friction. All case studies were pressure dominated which is consistent with the shock-filled flow fields. 


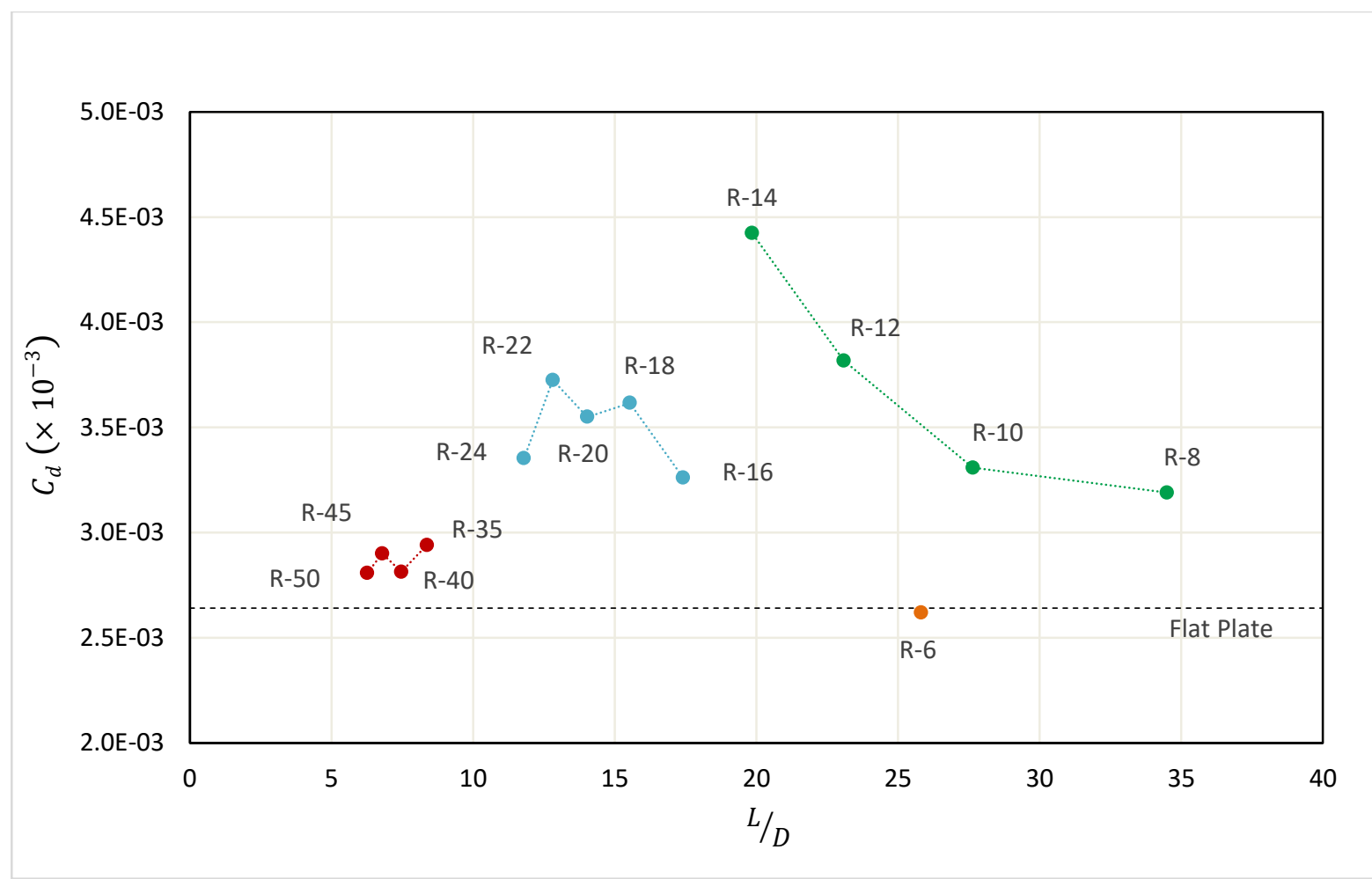

Fig. 5. Total drag coefficient

The special case R- 6 has almost the same drag force value as the flat plate, although exhibits a slight increase in pressure drag which could be attributed to the reattachment shock shortly after the BFS. Closed cavity cases R-8 - R-14 displayed an almost exponential increase in the total drag coefficient. There is a significant increase in the pressure component of the total drag force and a slight decrease in skin friction drag. This is due to the reattachment and detachment shocks on the cavity floor. Case R-14 has the lowest skin friction component relative to total drag of all the case studies which is less than half of that of the flat plate. From the results obtained herewith, it can be concluded that the flow phenomena associated with separation caused by forward-facing steps in closed cavity-type topologies contributed the most to the total drag. Case studies R-16-R-24 had a combination of several cavity flow regimes. $\mathrm{R}-18-\mathrm{R}-22$ had a mixture of open and closed cavity-type configurations and exhibited higher total drag coefficient compared to cases R-24 and R-16. Just like the purely closed cavity flow cases, this is due to the flow separation phenomena. Purely open cavity cases R-35 - R-50 displayed a significantly smaller drag coefficient closer to the flat plate values. With the reduction of the wavelength $\lambda$ and cavity L/D ratios, the spatial distribution of the roughness elements increases effectively making this a d-type roughness topology. The lower drag coefficient is due to the positive effects of the trapped coherent vortical structure within the cavities. Consistent with this, cases R-35 - R-50 recorded the lowest skin friction drag values compared to all other topology variants investigated. 


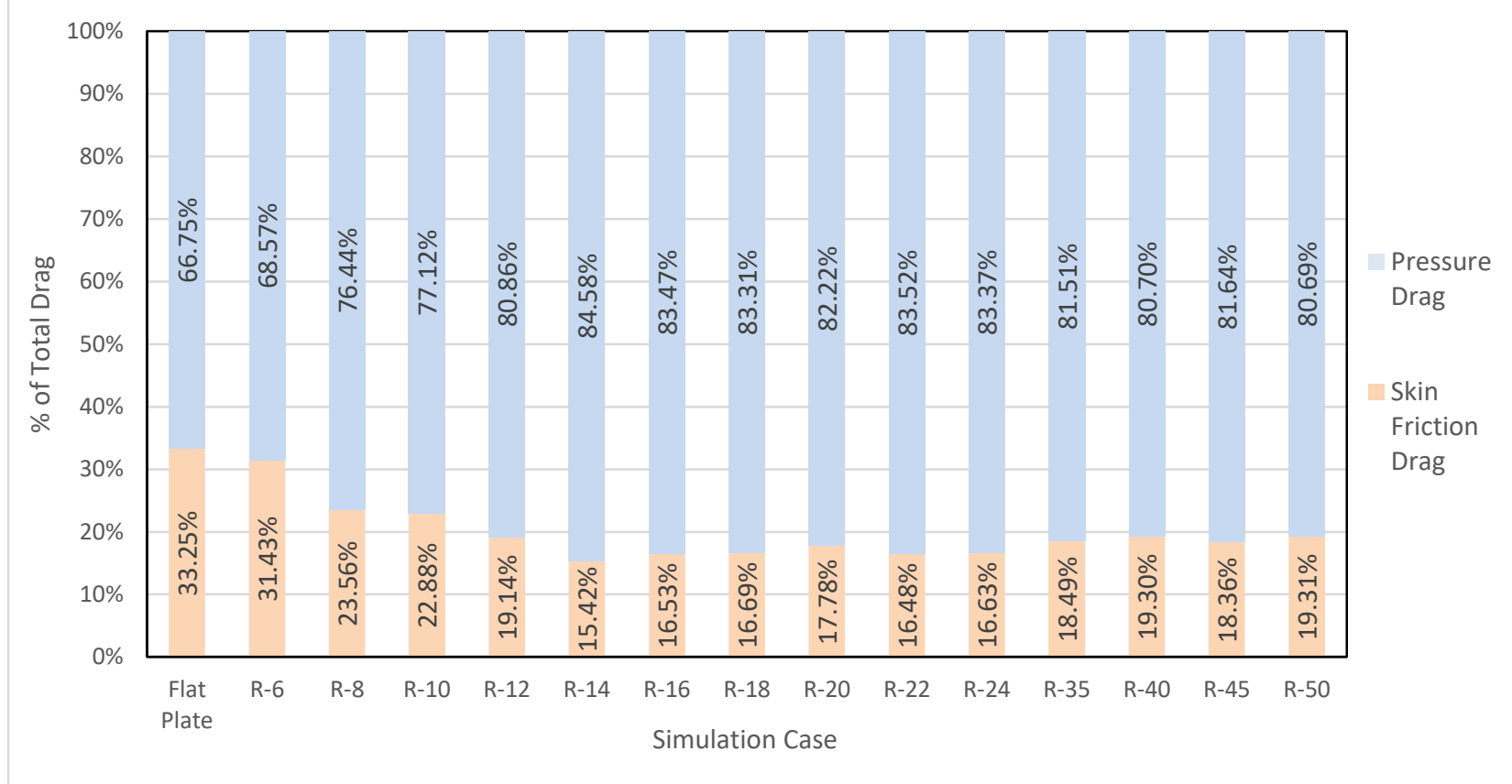

Fig. 6. Percentage of total drag force attributed to pressure and skin friction

\section{Conclusions}

A numerical method was employed to provide qualitative insight into the TBL and flow field distortions caused by periodic surface roughness elements in the form of steps and cavities under Mach 3.0 flow conditions. Notably, for all geometrical variants, it was found that the compressibility effects caused by the topologies permeated the entire boundary layer and extended into the freestream. Cavity L/D ratios of $19.8-23.1$ and $12.8-15.5$ yielded the highest drag coefficients. The flow field over these periodic arrays exhibited closed and a combination of closed cavity-type features and it can be concluded that the flow phenomena associated with separation caused by forward-facing steps in closed cavity-type topologies contributed the most to the total drag. L/D ratios of $6.3-8.4$ exhibited the lowest drag coefficient. The lower drag coefficient is due to the positive effects of the trapped coherent vortical structure within the cavities. Consistent with this, cases R-35 - R-50 recorded the lowest skin friction drag values compared to all other topology variants investigated. It is also noted that pressure forces become more dominant as the surface wavelength is decreased.

\section{Acknowledgement}

The authors would like to acknowledge the financial support from Universiti Sains Malaysia under the Short Term Grant Scheme (304/PAERO/6315444) in carrying out this research.

\section{References}

[1] Semenov, V. V., I. E. Ivanov, and I. A. Kryukov. "Dvukhkonturnoe shchelevoe soplo raketnogo dvigatelya [Dual-bell slot nozzle of Rocket engine]." Vestnik Permskogo natsionalnogo issledovatelskogo politekhni-cheskogo universiteta. Aerokosmicheskaya tekhnika 46 (2016): 56-72.

https://doi.org/10.15593/2224-9982/2016.46.03

[2] Hagemann, Gerald, Hans Immich, Thong Van Nguyen, and Gennady E. Dumnov. "Advanced rocket nozzles." Journal of Propulsion and Power 14, no. 5 (1998): 620-634.

https://doi.org/10.2514/2.5354 
[3] Semenov, V. V., I. E. Ivanov, and I. A. Kryukov. "Regulirovanie vysotnosti sopla s bolshoy stepenyu rasshireniya [Control of nozzle design altitude with high expansion ratio]." PNRPU Aerospace Engineering Bulletin 40 (2015): 521.

https://doi.org/10.15593/2224-9982/2015.40.1

[4] Stark, Ralf, Chloé Génin, Dirk Schneider, and Christian Fromm. "Ariane 5 performance optimization using dual-bell nozzle extension." Journal of Spacecraft and Rockets 53, no. 4 (2016): 743-750. https://doi.org/10.2514/1.A33363

[5] Stark, Ralf, and Chloé Génin. "Sea-level transitioning dual bell nozzles." CEAS Space Journal 9, no. 3 (2017): 279 287.

https://doi.org/10.1007/s12567-017-0154-8

[6] Zmijanovic, Vladeta, Luc Leger, Mohamed Sellam, and Amer Chpoun. "Assessment of transition regimes in a dualbell nozzle and possibility of active fluidic control." Aerospace Science and Technology 82 (2018): 1-8. https://doi.org/10.1016/i.ast.2018.02.003

[7] Gradl, Paul R., and Peter Valentine. "Carbon-Carbon Nozzle Extension Development in Support of In-space and Upper-Stage Liquid Rocket Engines." In 53rd AIAA/SAE/ASEE Joint Propulsion Conference, p. 5064. 2017.

https://doi.org/10.2514/6.2017-5064

[8] Kochetkov, Yu, I. Borovik, O. Podymova, and A. Protopopov. "Variety of gas-dynamic turbulent configurations at internal flow in channels of structurally complex bodies." MS\&E 779, no. 1 (2020): 012030.

https://doi.org/10.1088/1757-899X/779/1/012030

[9] Laganelli, A. L., and R. E. Zempel. "Observations of surface ablation patterns in subliming materials." AIAA Journal 8, no. 9 (1970): 1709-1711. https://doi.org/10.2514/3.5973

[10] Swigart, Rudolph J. "Cross-Hatching Studies-A Critical Review." AIAA Journal 12, no. 10 (1974): 1301-1318. https://doi.org/10.2514/3.49482

[11] Semenov, V. V. "Wave drag of streamlined corrugated surfaces of jet nozzle and flight vehicle." Izvestiya vyisshih uchebnyih zavedeniy. Aviatsionnaya tehnika, no. 4 (2000): 18-22.

[12] Sergienko, A. A., and V. V. Semenov. "Study of wave resistance of the rhombic relief surface of the propulsive nozzle wall." Izvestiya vyisshih uchebnyih zavedeniy. Aviatsionnaya tehnika, no. 1 (2001): 30-33.

[13] Latin, Robert M., and Rodney DW Bowersox. "Flow properties of a supersonic turbulent boundary layer with wall roughness." AIAA journal 38, no. 10 (2000): 1804-1821.

https://doi.org/10.2514/2.862

[14] Ekoto, Isaac W., Rodney DW Bowersox, Thomas Beutner, and Larry Goss. "Response of supersonic turbulent boundary layers to local and global mechanical distortions." Journal of Fluid Mechanics 630 (2009): 225-265. https://doi.org/10.1017/S0022112009006752

[15] Semenov, V. V., V. A. Volkov, M. C. Kwon, and J. S. S. Sidhu. "Wave resistance defect in a planar flow over periodic reliefs." Russian Aeronautics (Iz VUZ) 59, no. 2 (2016): 211-217. https://doi.org/10.3103/S1068799816020094

[16] Volkov, V. A., V. V. Semenov, and J. S. S. Sidhu. "Wave drag of planar periodic relief structures." Trudy MAI no. 93 (2017).

[17] Van Pelt, H., B. W. Van Oudheusden, F. F. J. Schrijer, L. J. Souverein, and K. Seeliger. "Flow Categorization in Supersonic Flows with Large Roughness Heights." Proceedings of the 19th Australasian Fluid Mechanics Conference (2014).

[18] Menter, Florian R. "Two-equation eddy-viscosity turbulence models for engineering applications." AIAA journal 32 , no. 8 (1994): 1598-1605. https://doi.org/10.2514/3.12149

[19] Adni Mustaffa, Siti Hajar, Fatimah Al-Zahrah Mohd Saat, and Ernie Mattokit. "Numerical Study of the Entrance Effects in an Oscillatory Flow of a Standing-Wave Thermoacoustics." Journal of Advanced Research in Fluid Mechanics and Thermal Sciences 43, no. 1 (2018): 149-157.

[20] Khalil, Hesham, Khalid Saqr, Yehia Eldrainy, and Walid Abdelghaffar. "Aerodynamics of a trapped vortex combustor: A comparative assessment of RANS based CFD models." Journal of Advanced Research in Fluid Mechanics and Thermal Sciences 43, no. 1 (2018): 1-19. 